\title{
Characterization of Precipitation in Al-Li Alloy AA2195 by means of Atom Probe Tomography and Transmission Electron Microscopy
}

\author{
Muna Khushaim, ${ }^{1}$ Torben Boll, ${ }^{2}$ Judith Seibert, ${ }^{3}$ Ferdinand Haider, ${ }^{3}$ and Talaat Al-Kassab \\ ${ }^{1}$ Physical Sciences and Engineering Division, King Abdullah University of Science and Technology (KAUST), \\ Thuwal 23955-6900, Saudi Arabia \\ ${ }^{2}$ Department of Applied Physics, Chalmers University of Technology, 41296 Goteborg, Sweden \\ ${ }^{3}$ University of Augsburg, Institute of Physics, 86159 Augsburg, Germany
}

Correspondence should be addressed to Muna Khushaim; muna.khushaim@kaust.edu.sa

Received 22 January 2015; Accepted 19 May 2015

Academic Editor: Jan A. Jung

Copyright (C) 2015 Muna Khushaim et al. This is an open access article distributed under the Creative Commons Attribution License, which permits unrestricted use, distribution, and reproduction in any medium, provided the original work is properly cited.

\begin{abstract}
The microstructure of the commercial alloy AA2195 was investigated on the nanoscale after conducting T8 tempering. This particular thermomechanical treatment of the specimen resulted in the formation of platelet-shaped $\mathrm{T}_{1}\left(\mathrm{Al}_{2} \mathrm{CuLi}\right) / \theta^{\prime}\left(\mathrm{Al}_{2} \mathrm{Cu}\right)$ precipitates within the $\mathrm{Al}$ matrix. The electrochemically prepared samples were analyzed by scanning transmission electron microscopy and atom probe tomography for chemical mapping. The $\theta^{\prime}$ platelets, which are less than $2 \mathrm{~nm}$ thick, have the stoichiometric composition consistent with the expected $\mathrm{Al}_{2} \mathrm{Cu}$ equilibrium composition. Additionally, the Li distribution inside the $\theta^{\prime}$ platelets was found to equal the same value as in the matrix. The equally thin $\mathrm{T}_{1}$ platelet deviates from the formula $\left(\mathrm{Al}_{2} \mathrm{CuLi}\right)$ in its stoichiometry and shows $\mathrm{Mg}$ enrichment inside the platelet without any indication of a higher segregation level at the precipitate/matrix interface. The deviation from the $\left(\mathrm{Al}_{2} \mathrm{CuLi}\right)$ stoichiometry cannot be simply interpreted as a consequence of artifacts when measuring the $\mathrm{Cu}$ and $\mathrm{Li}$ concentrations inside the $\mathrm{T}_{1}$ platelet. The results show rather a strong hint for a true lower $\mathrm{Li}$ and $\mathrm{Cu}$ contents, hence supporting reasonably the hypothesis that the real chemical composition for the thin $\mathrm{T}_{1}$ platelet in the T8 tempering condition differs from the equilibrium composition of the thermodynamic stable bulk phase.
\end{abstract}

\section{Introduction}

One of the upcoming materials used for the structural components of aircrafts is aluminum-lithium alloys. This class of alloys is commonly selected because it exhibits an enhanced strength/weight ratio that makes it an attractive material for weight critical applications. A series of Al-Li-Cu alloys with minor amount of $\mathrm{Mg}, \mathrm{Ag}$, and $\mathrm{Zr}$ known as Weldalite that exhibit desirable combinations of strength and toughness have been developed in recent years [1].

The current study focuses on one member of the Weldalite family, namely, the commercial AA2195 alloy, which is considered as a promising candidate for aerospace applications due to its high strength, high modulus, low density, good corrosion resistance, excellent fatigue properties, and fracture toughness at cryogenic temperatures [2]. The alloy exhibits superior mechanical properties after processing a thermomechanical treatment termed "T8." This treatment begins with a solution treatment in a single phase region, followed by quenching to obtain a supersaturated solid solution. Plastic deformation (cold working) is then applied to the samples. The final stage is an artificial aging far below the temperature of the strengthening phase solvus line [3]. It has been shown that alloy conducting T8 tempering has a combination of excellent fracture toughness $(\sim 60 \mathrm{MPa} \sqrt{\mathrm{m}})$ and an improved strength ( $550 \mathrm{MPa})$ [4]. The presence of various microalloying elements at a variable volume fraction and adequate subsequent treatment causes the precipitation 
TABLE 1: Chemical composition of alloying elements in AA2195.

\begin{tabular}{lcccccr}
\hline Alloying element & $\mathrm{Cu}$ & $\mathrm{Li}$ & $\mathrm{Mg}$ & $\mathrm{Ag}$ & $\mathrm{Zr}$ & \multicolumn{2}{c}{$\mathrm{Al}$} \\
\hline Nominal (wt.\%) & 4 & 1 & 0.36 & 0.28 & 0.14 & 94.22 \\
Nominal (at.\%) & 1.69 & 3.87 & 0.39 & 0.06 & 93.95 \\
ICP (at.\%) & $1.74 \pm 0.19$ & $3.67 \pm 0.05$ & $0.36 \pm 0.01$ & $0.08 \pm 0.02$ & $0.04 \pm 0.0004$ & $94.11 \pm 0.27$ \\
\hline
\end{tabular}

of different possible phases within the Weldalite family such as $\mathrm{T}_{1}\left(\mathrm{Al}_{2} \mathrm{CuLi}\right), \theta^{\prime}\left(\mathrm{Al}_{2} \mathrm{Cu}\right), \beta^{\prime}\left(\mathrm{Al}_{3} \mathrm{Zr}\right)$, and $\delta^{\prime}\left(\mathrm{Al}_{3} \mathrm{Li}\right)$. The $\mathrm{T}_{1}$ phase has a plate-shaped morphology lying on $\{111\}$ planes and is the primary phase responsible for the strengthening effect in AA2195 at temperatures below $533 \mathrm{~K}$ [5]. The nucleation of this phase is difficult without the presence of secondary alloying elements such as $\mathrm{Mg}$ and $\mathrm{Ag}$, which can offer nucleation sites within the matrix for this phase [6]. The nucleation of the $T_{1}$ phase also depends on the application of plastic deformation prior to artificial aging [7]. Applying this plastic deformation prior to artificial ageing will increase the number of the nucleation sites for the $\mathrm{T}_{1}$ phase and hence promote a uniform distribution of heterogeneously nucleated $\mathrm{T}_{1}$ precipitates. These precipitates will act as nonshearable obstacles to dislocation motion and promote slip homogenization [4].

The $\mathrm{T}_{1}$ phase coexists with the $\theta^{\prime}\left(\mathrm{Al}_{2} \mathrm{Cu}\right)$ phase which lies as plates on the $\{100\}$ matrix planes [8]. This phase is dominant in the early stage of the heat treatment at elevated temperatures $588-644 \mathrm{~K}$ [5]. In addition to the $\mathrm{T}_{1}$ and $\theta^{\prime}$ phases, $\mathrm{Zr}$ forms coherent spherical $\beta^{\prime}\left(\mathrm{Al}_{3} \mathrm{Zr}\right)$ precipitates with $\mathrm{L}_{2}$-structure that can already form during the alloying process within the melt. They are designed to control the grain structure and degree of recrystallization after the solidification of the ingot [9]. Finally, the $\delta^{\prime}\left(\mathrm{Al}_{3} \mathrm{Li}\right)$ is usually reported to precipitate upon quenching from the melt for alloy compositions higher than 5 at.\% Li in the matrix [1012].

Atom probe studies have provided a range of information on the different types of precipitates present in Al-Li-Cu alloys. Murayama and Hono [13] reported their observation of $\mathrm{Mg}$ clusters at the early stage of aging and the possibility of the segregation of $\mathrm{Mg}$ and $\mathrm{Ag}$ atoms to the broad interface of the $\mathrm{T}_{1}$ plates. Moreover, Gault et al. [14] studied the early stages of clustering, precipitate interactions, solute segregation at the matrix/precipitate interfaces, and the chemical composition of the different phases.

The aim of this study is to characterize the different precipitates that dominate the microstructure of the AA2195 alloy. Since the composition evaluation of subnanometer scale platelet precipitates is extremely difficult, atom probe tomography has been employed to characterize the local chemical composition of the precipitates and to determine the location of the various alloying atoms.

\section{Material and Methods}

The chemical composition of AA2195 is shown in Table 1. The table shows the nominal composition for the alloy and the measured composition by inductively coupled plasma optical emission spectrometry (Varian ICP-OES 720-ES). Samples in the form of ingots were obtained in a T8 temper state. Samples on the T8 condition were solution treated for $1 \mathrm{~h}$ to $783 \mathrm{~K}$, quenched, stretched to $3 \%$, and subsequently aged to $423 \mathrm{~K}$ for $30 \mathrm{~h}$.

Vickers microhardness measurements were performed using a load of $0.2 \mathrm{~kg}$ applied on the sheet sample. The Vickers hardness number (VHN), which was obtained by averaging ten measurements, was found to be $(160 \pm 7) \mathrm{HV} / 1.96$ and thus confirms the success of the heat treatment.

Small rods $(0.3 \mathrm{~mm} \times 0.3 \mathrm{~mm} \times 10 \mathrm{~mm})$ were spark machined from the bulk and then electropolished to a sharp needle-shaped specimen for atom probe tomography (APT) analyses and scanning transmission electron microscopy (STEM). Electropolishing was carried out using a solution of 30 vol.\% nitric acid in methanol at temperatures between 253 and $298 \mathrm{~K}$ in the range of 5-7 V. The specimens were prepared for transmission electron microscopy (TEM) by standard twin-jet electropolishing using a solution of 30 vol. $\%$ nitric acid in methanol at $243 \mathrm{~K}$.

STEM images were recorded using a Titan CT with a dedicated APT holder (E.A. Fischione 2025 Tomoholder). TEM analysis was carried out using a Jeol2100F, operated at $200 \mathrm{kV}$. The APT experiments were performed on both the Cameca laser assisted wide angle tomographic atom probe (LAWATAP) in the voltage mode at temperatures between 25 and $30 \mathrm{~K}$ with a pulse fraction between $20 \%$ and $22.5 \%$ at a vacuum level of $10^{-8} \mathrm{~Pa}$ and the Cameca local electrode atom probe (LEAP- $4000 \mathrm{HR}$ ) in the voltage mode at $22 \mathrm{~K}$ and $18 \%$ of pulse fraction at $10^{-8} \mathrm{~Pa}$.

The obtained data was visualized using the TAP3D and IVAS software programs provided by Cameca. The compositions of the precipitates were measured quantitatively using the proximity histogram (proxigram) technique [15]. In this methodology, an isoconcentration surface is first defined in the reconstructed volume to delineate the precipitates. Then, starting at the isoconcentration surface, which is the origin of the proxigram, and moving toward the center of precipitates (positive distance), the composition of the precipitate is measured in discrete shells with the shape of isoconcentration surface at fixed intervals. The matrix composition is obtained by starting at the isoconcentration surface and moving into the matrix (negative distance). All proxigrams, in this study, were computed with a $0.1 \mathrm{~nm}$ bin size. To increase the statistical accuracy of the composition, bins containing fewer than 50 atoms were eliminated.

An isoconcentration surface is the surface that envelops a volume with concentrations higher than the selected concentration of one or more elements. This surface was obtained by sampling the atom probe tomography reconstruction with 


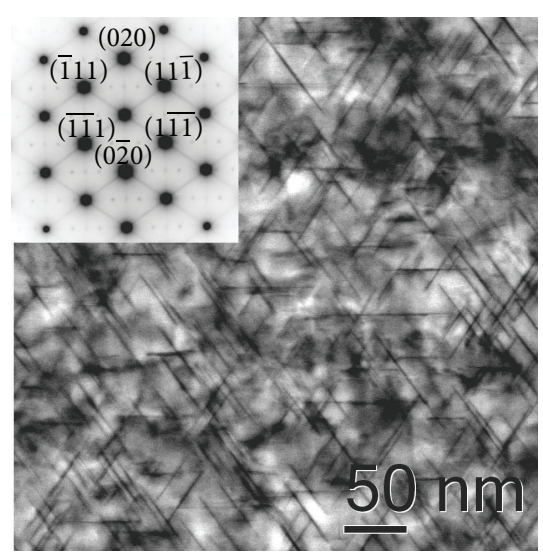

(a)

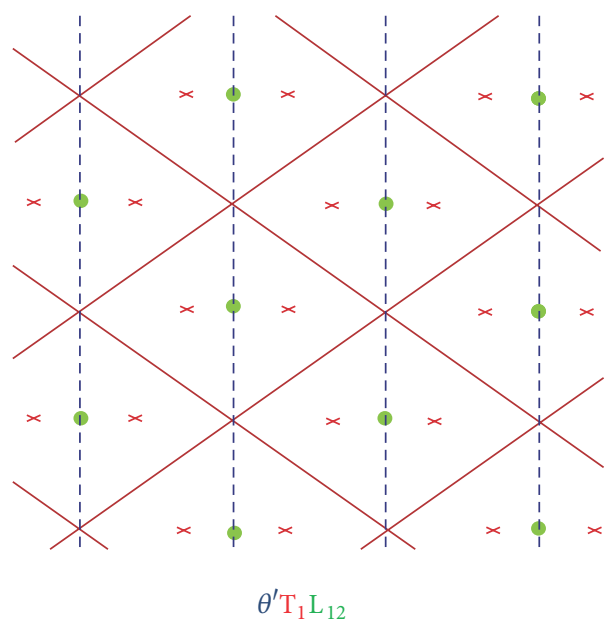

(b)

FIGURE 1: Evolution of the microstructure as observed by TEM. (a) Typical bright field image showing a complex microstructure with the $\mathrm{T}_{1}$, $\theta^{\prime}$, and $\beta^{\prime}$ precipitates and the corresponding [101] selected area diffraction pattern (SADP). (b) Schematic of a simulated diffraction pattern that assigns the reflections and streaks in the SADP to the corresponding precipitates.

$0.8 \times 0.8 \times 0.8 \mathrm{~nm}^{3}$ voxels after applying a delocalization procedure developed by Hellman et al. [16] with smoothing parameters of $1.5 \mathrm{~nm}$ for the $x$ and $y$ coordinates and $0.75 \mathrm{~nm}$ for the $z$ coordinate.

\section{Results and Discussion}

Several different precipitates were identified in AA2195 and are discussed below.

3.1. Electron Microscopy. Conventional TEM bright field images revealed a complex microstructure encompassing different precipitates with platelet and spherical morphologies as shown in Figure 1. Precipitates were characterized using an exact [110] zone to detect $\mathrm{T}_{1}$ platelets, $\theta^{\prime}$ platelets, and spherical precipitates with $\mathrm{L}_{2}$-structure. A schematic of the indexed selected area diffraction pattern (SADP) in the [101] direction is integrated with the bright field-TEM image (Figure 1(a)). This indicates the presence of two variants of $\mathrm{T}_{1}$ precipitate as streaks along the $\langle 111\rangle$ direction in the pattern. The other two variants of this phase produce spots adjacent to $\langle 200\rangle$ positions. The streaks along the $\langle 200\rangle$ direction reveal the presence of one variant of $\theta^{\prime}$. The superlattice reflections in the diffraction pattern may originate from an $\mathrm{L}_{2}$-ordered structure representing $\delta^{\prime}\left(\mathrm{Al}_{3} \mathrm{Li}\right)$ and/or $\beta^{\prime}\left(\mathrm{Al}_{3} \mathrm{Zr}\right)$ precipitates. The $\mathrm{L}_{2}$ unit cell is based on the face centered cubic (fcc) unit cell of aluminum. However, the corner atoms are replaced by either $\mathrm{Li}$ or $\mathrm{Zr}$, respectively. This means that all $\langle 100\rangle$ directions are superstructure directions. The spherical precipitates are most probably of the $\beta^{\prime}$-type, since the $\mathrm{Li}$ composition in the investigated alloy is less than 5 at.\%. It is worth noting that, from the diffraction pattern alone, no decision can be achieved whether the precipitates are $\delta^{\prime}$ or $\beta^{\prime}$ because of the similarity of the lattice constant. Figure 1(b) presents a simulated diffraction pattern matching all spots and streaks in the [101] selected area diffraction pattern.

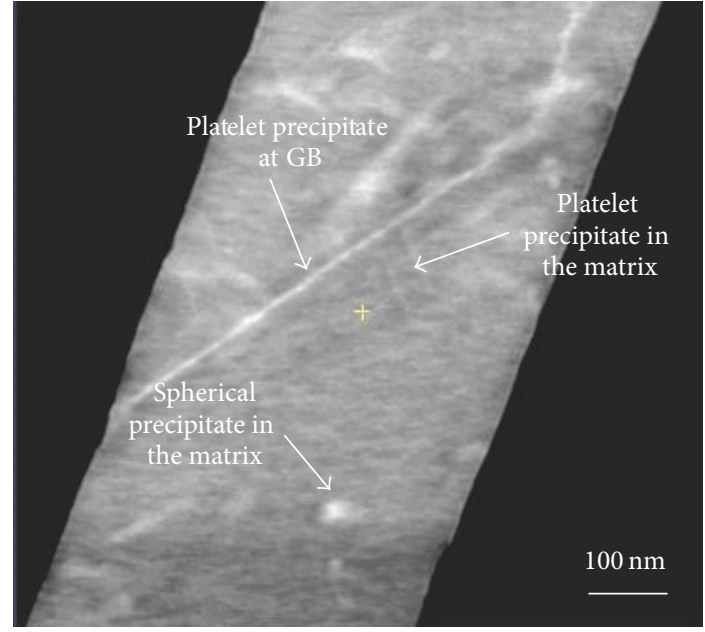

FIGURE 2: High angle annular bright field scanning transmission electron microscopy image showing the heterogeneous formation of a bright imaging platelet precipitate at the grain boundary and the distribution of platelets and spherical precipitates within the matrix.

High angle annular bright field scanning transmission electron microscopy (HAABF) STEM-contrast also revealed the existence of both spherical and platelet precipitates (Figure 2). As illustrated in Figure 2, the heterogeneous formation of platelet precipitate can be clearly observed at grain boundaries by imaging the sample from different angles $\left( \pm 75^{\circ}\right.$ in steps of $\left.1^{\circ}\right)$. A low angle grain boundary in Figure 2 was identified while rotating the specimen and monitoring the diffraction pattern at various locations within the sample. Moreover, the distribution of platelet precipitates and spherical precipitates within the matrix could be observed. The heterogonous nucleation site of the $T_{1}$ phase on the grain boundary agrees well with the previous observation reported by Cassada et al. [7], who proposed that the precipitation of 

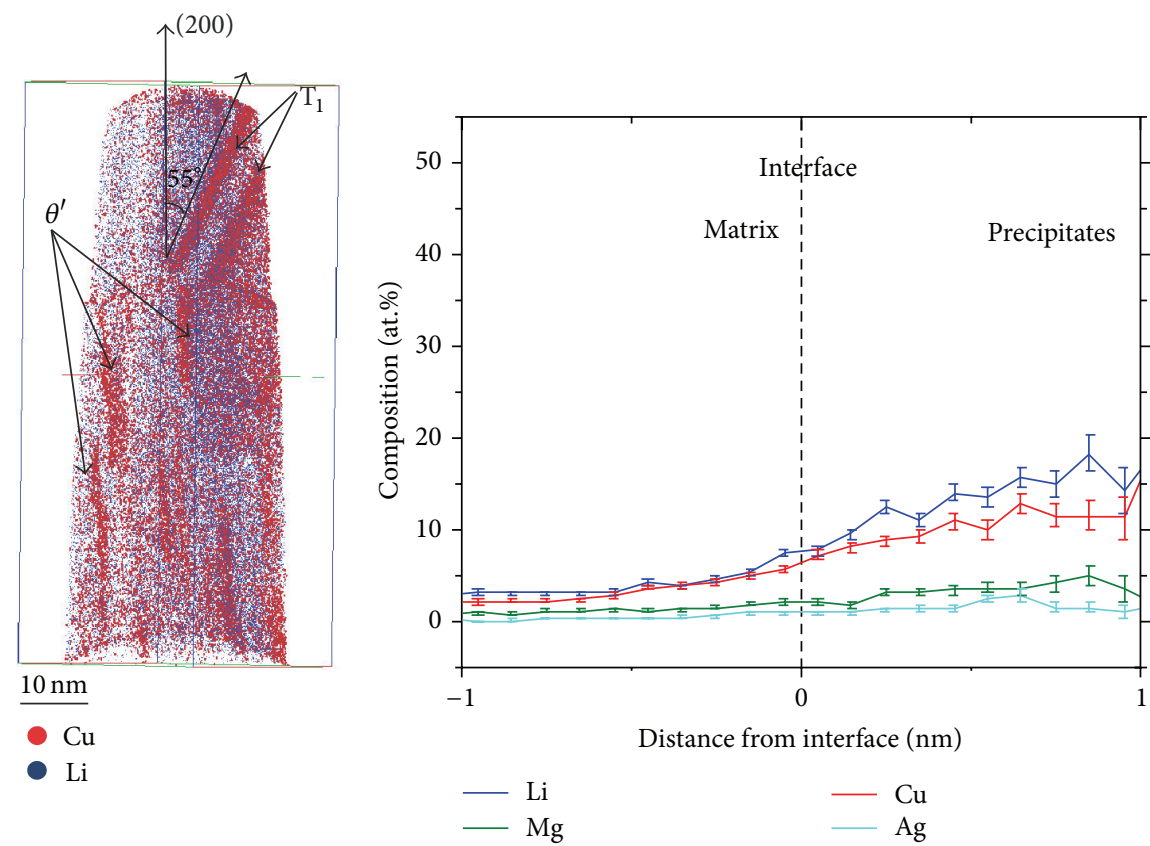

(a)

(b)

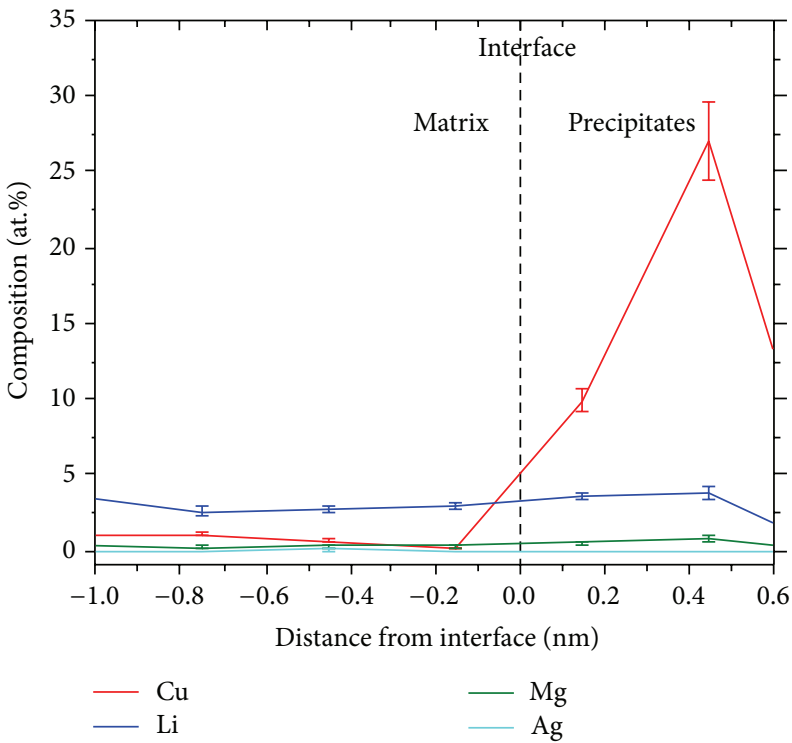

(c)

FIGURE 3: LAWATAP analysis of the microstructure at $30 \mathrm{~K}$ and $20 \%$ of pulse fraction. (a) Reconstructed volume showing the distribution of the $\mathrm{T}_{1}$ and $\theta^{\prime}$ phases. (b) Corresponding proxigram composition profile for the $\mathrm{T}_{1}$ platelet indicating chemical composition of (11 \pm 1$)$ at. $\%$ $\mathrm{Cu},(13 \pm 1)$ at. $\% \mathrm{Li},(3 \pm 1)$ at. $\% \mathrm{Mg}$, and $(1.5 \pm 0.4)$ at. $\% \mathrm{Ag}$. (c) Corresponding combined proxigram composition profile for the $\theta^{\prime}$ platelet with a chemical composition of $(27 \pm 3)$ at. $\% \mathrm{Cu},(3.8 \pm 0.2)$ at. $\% \mathrm{Li}$, and $(0.7 \pm 0.2)$ at. $\% \mathrm{Mg}$.

the $\mathrm{T}_{1}$ phase at subgrain boundaries results from the easy migration of $\mathrm{Cu}$ and $\mathrm{Li}$ atoms and the sufficient concentration of mobile vacancies at these locations. Moreover, Lee et al. [17] observed that an increase in aging time caused a rapid precipitation of the $T_{1}$ phase both within the matrix and at subgrain boundaries, consistent with the (HAABF) STEM image presented in Figure 2.

3.2. Atom Probe Tomography Analyses. The presence of several alloying elements such as $\mathrm{Li}, \mathrm{Cu}, \mathrm{Mg}, \mathrm{Zr}$, and $\mathrm{Ag}$ in
AA2195 leads to complex interactions between the different types of precipitates, which has led to many studies on the evolution of such precipitates in alloys. The use of atom probe tomography allows for the determination of the chemical composition within small-thickness platelets (less than $2 \mathrm{~nm}$ ) embedded in an $\mathrm{Al}$ matrix as discussed in this section.

3.2.1. LAWATAP Analyses at $30 \mathrm{~K}$ and $20 \%$ of Pulse Fraction. Figure 3 shows the reconstructed volume of the sample analyzed by a LAWATAP at $30 \mathrm{~K}$ and $20 \%$ of pulse fraction 
(ratio of pulse voltage, $V_{\text {pulse, }}$ to DC standing voltage, $\left.V_{\text {DC }}\right)$.

This figure demonstrates that platelet precipitates are distributed within the matrix. Based on the knowledge of the angles between different crystallographic directions, it can be confirmed that the two plates in the upper part of the reconstructed volume are $T_{1}$ precipitates. The direction of the analysis has been identified as $\langle 200\rangle$. This identification is based on measuring the distance between the atomic planes in the atom probe tomography dataset that are perpendicular to this zone axis, that is, the $\langle 200\rangle$ direction. As shown in Figure 3(a), the angle between the normal of the $T_{1}$ platelet plane, the $\langle 111\rangle$ direction, and the $\langle 200\rangle$ zone axis was found to be $\left(55^{\circ} \pm 1\right)$, which is within the margin of error for the expected crystallographic angle between these two directions (the calculated value of this angle from the unit cell is $54.76^{\circ}$ ). Due to their orientations perpendicular to the $\langle 200\rangle$ zone axis, the remaining platelets in the reconstructed volume can be identified as $\theta^{\prime}$ precipitates.

A combined corresponding proxigram profile for the $\mathrm{T}_{1}$ platelets is shown in Figure $3(\mathrm{~b})$. The $\mathrm{T}_{1}$ precipitates are delineated by 6 at.\% $\mathrm{Li}$ isoconcentration surface. The chemical composition for the $\mathrm{T}_{1}$ platelets was found to be $(11 \pm 1)$ at. $\% \mathrm{Cu},(13 \pm 1)$ at. $\% \mathrm{Li},(3 \pm 1)$ at. $\% \mathrm{Mg}$, and $(1.5 \pm 0.4)$ at. $\% \mathrm{Ag}$, indicating a clear deviation from the $\left(\mathrm{Al}_{2} \mathrm{CuLi}\right)$ stoichiometry. A combined proxigram profile from 4 at. $\% \mathrm{Cu}$ isoconcentration surfaces of $\theta^{\prime}$ platelets is shown in Figure 3(c). According to this profile, the chemical composition for the $\theta^{\prime}$ precipitates was found to be $(27 \pm$ 3) at. $\% \mathrm{Cu},(3.8 \pm 0.2)$ at. $\% \mathrm{Li}$, and $(0.7 \pm 0.2)$ at. $\% \mathrm{Mg}$. This quantitative analysis reveals a clear evidence for a significant concentration level of $\mathrm{Li}$ atoms inside the $\theta^{\prime}$ platelets, without any indication for the presence of Ag or $\mathrm{Zr}$. The chemical compositions for these platelets are very close to the $\left(\mathrm{Al}_{2} \mathrm{Cu}\right)$ stoichiometry. The partitioning of Li atoms to the $\theta^{\prime}$ precipitates might indicate the possible occurrence of the phase transformation of the $\theta^{\prime}$ precipitates at the later stages of the ageing.

To obtain a high spatial resolution perpendicular to the platelets, it is desirable to align this direction with the tip axis of the prepared samples. Since the material possesses a strong rolling texture (sheet normal to $\{110\}$ planes, rolling direction is $\langle 112\rangle)$, it is possible to prepare samples with a defined orientation; for example, samples were prepared with their axis parallel to the $\langle 111\rangle$ direction. Figure 4 shows APT results for such preferentially oriented samples. The (111) Al atomic planes can be identified. Thus, three out of four orientations of one $\mathrm{T}_{1}$ precipitate on the $\{111\}$ matrix planes can be observed (Figure 4(a)). The magnified view of one $\mathrm{T}_{1}$ platelet with resolved $\{111\}$ planes is shown in Figure 4(b). Figure 4(c) is a proxigram profile from 4 at.\% $\mathrm{Cu}$ isoconcentration surface of the $\mathrm{T}_{1}$ platelet. Even though that the measured chemical composition for this platelet was improved by preforming an APT analysis in this direction, the deviation from the stoichiometric value can be clearly seen in the chemical composition of $(14 \pm 2)$ at. $\% \mathrm{Cu},(14 \pm 3)$ at. $\% \mathrm{Li},(4 \pm 1)$ at. $\% \mathrm{Mg}$, and $(1.4 \pm 0.4)$ at. $\% \mathrm{Ag}$. This quantitative analysis demonstrates the enrichment of $\mathrm{Mg}$ atoms inside the platelet without any indication for enrichment at the interface. Furthermore, there is no statistical significant enrichment of $\mathrm{Ag}$ or $\mathrm{Zr}$. This corresponds with previous observation reported by Gault et al. [14].

The deviation of the experimentally measured chemical composition of the $\mathrm{T}_{1}$ platelet to the $\left(\mathrm{Al}_{2} \mathrm{CuLi}\right)$ stoichiometry has been observed by Murayama and Hono [13] as well. They interpreted this deviation as a result of the unstable ionization behavior of atoms near or within the $\mathrm{T}_{1}$ precipitates resulting from the very low evaporation field of Li. Moreover, Gault et al. [14] interpret this deviation as a result of a convolution of the matrix concentration with that of the precipitates due to the presence of trajectory aberrations in the APT analyses. This artifact leads to an overestimation of the $\mathrm{Al}$ content inside the platelet. However, significant notes could be observed on the correction method suggested by Gault et al. [14]. Most notably, the assumption of having correct aluminum contents in all precipitates and calculating their chemical composition as a function of apparent aluminum concentration enhances the uncertainties of their measured chemical composition.

As far as the trajectory aberrations are concerned, the thickness of the platelets will be overestimated in the $3 \mathrm{D}$ reconstructed volume (Figures 3(a) and 4(a)). However, an accurate platelet thickness can be determined by counting the atomic planes of the Al-rich matrix in the $\langle 111\rangle$ direction. By multiplying the number of $\mathrm{Al}$ atomic planes by the interplanar spacing of $a / \sqrt{\left(h^{2}+k^{2}+l^{2}\right)}$ (where $a$ is the lattice parameter for fcc Al, $a=0.405 \mathrm{~nm}$, and $h=k=l=1$ ) the $\mathrm{T}_{1}$ platelet thickness was found to be $(1.4 \pm 0.2) \mathrm{nm}$. As the presence of different alloying elements with low chemical concentrations [18] does not affect largely the value of the lattice parameter of the Al-rich matrix (Table 1), it can be justified to set the value of the lattice parameter for the Alrich matrix to be equal to that of pure Al. Furthermore, local magnification effects that cause variations in atomic density between matrix and precipitates [19] can lead to an underestimation of the $\mathrm{Li}$ and $\mathrm{Cu}$ content of the thin $\mathrm{T}_{1}$ platelets. These APT artifacts might affect the estimation of the chemical composition for the $\mathrm{T}_{1}$ platelets precipitates, and hence great care is required for the analyses of this phase. Menand et al. have reported optimized experimental conditions for the analysis of Al-Li alloys which allow minimizing such APT artifacts [10]. These conditions consist of a low tip temperature of 20 to $30 \mathrm{~K}$ and a pulse fraction of greater than $15 \%$. On this basis, atom probe tomography experiments were slightly changed.

\subsubsection{LAWATAP Analyses at $25 \mathrm{~K}$ and $22.5 \%$ of Pulse Fraction.} The series of images in Figure 5 reveals the effect of changing the experimental parameters on the detected chemical composition within the precipitates. Figure 5 (a) shows various $\mathrm{T}_{1}$ and $\theta^{\prime}$ platelets. The proxigram profiles were computed by following the same procedure as mentioned above. Proxigram profiles corresponding to $\theta^{\prime}$ and $\mathrm{T}_{1}$ platelets where $\theta^{\prime}$ precipitates are delineated by 10 at. $\% \mathrm{Cu}$ isoconcentration surfaces and $\mathrm{T}_{1}$ precipitates are delineated by 10 at.\% $\mathrm{Li}$ isoconcentration surfaces are presented in Figures 5(b) and 5(c), respectively. As illustrated in Figure 5(b), the chemical 


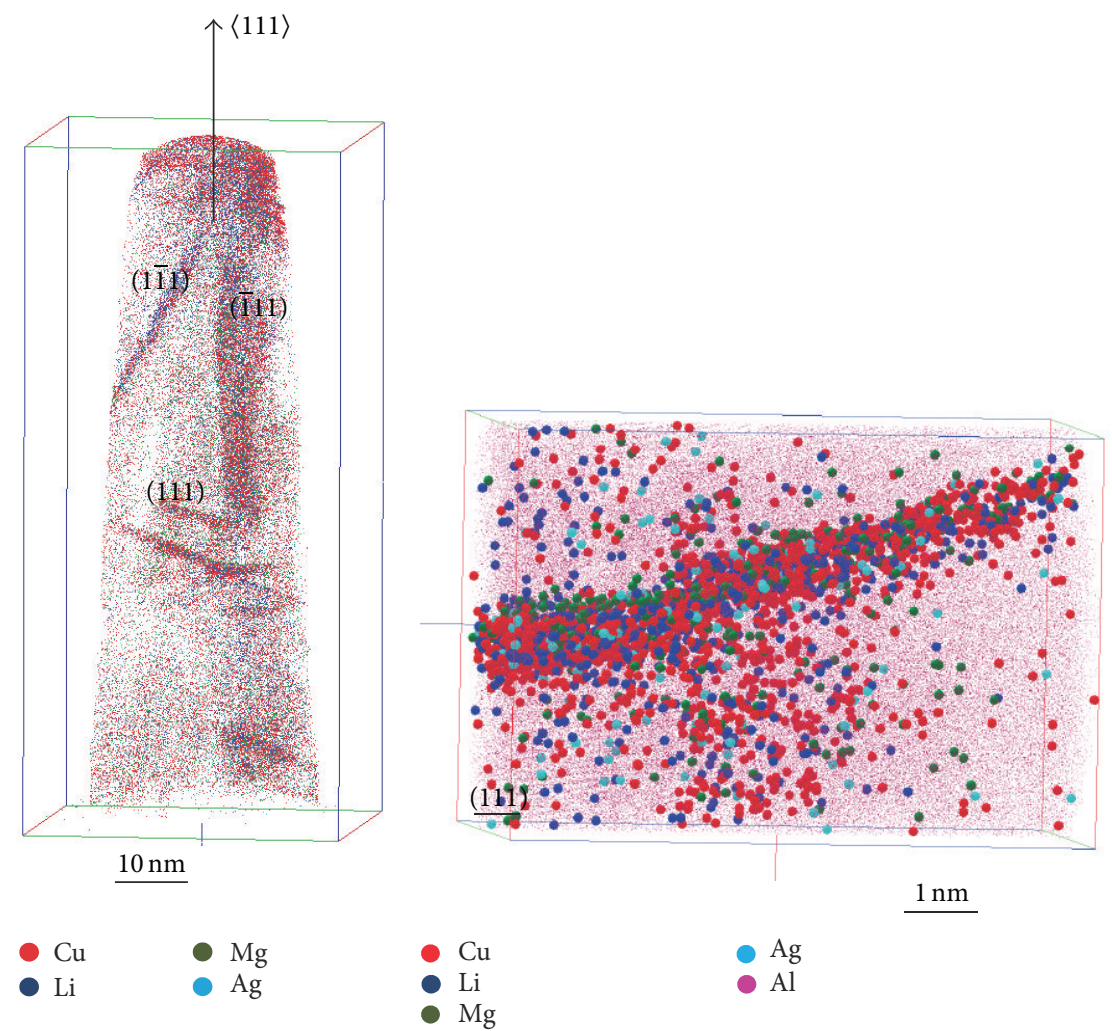

(a)

(b)

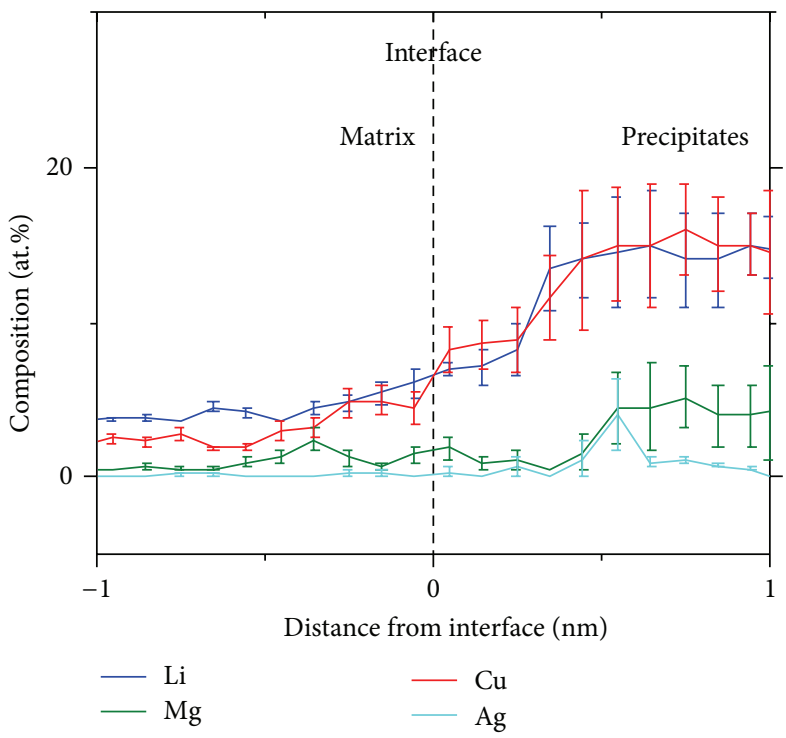

(c)

FIGURE 4: LAWATAP analysis for the specimen with rolling texture with the same experimental parameters as in Figure 3. (a) Reconstructed volume showing three out of four orientations of the $\mathrm{T}_{1}$ precipitate on the $\{111\}$ matrix planes. (b) Magnified view of the $\mathrm{T}_{1}$ platelet with resolved $\{111\}$ planes reveals the distribution of $\mathrm{Mg}$ within the $\mathrm{T}_{1}$ platelet. (c) Corresponding proxigram composition profile for the $\mathrm{T}_{1}$ platelet on the $\{111\}$ plane gives the chemical composition as $(14 \pm 2)$ at. $\% \mathrm{Cu},(14 \pm 3)$ at. $\% \mathrm{Li},(4 \pm 1)$ at. $\% \mathrm{Mg}$, and (1.4 \pm 0.4$)$ at. $\% \mathrm{Ag}$.

composition for $\theta^{\prime}$ was found to be $(30 \pm 2)$ at. $\% \mathrm{Cu},(3 \pm 1)$ at.\% $\mathrm{Li}$, and $(1 \pm 0.7)$ at.\% $\mathrm{Mg}$. It is worth noting that analyses of the $\theta^{\prime}$ precipitates under these experimental conditions resulted in $\theta^{\prime}$ stoichiometries consistent with the expected
$\left(\mathrm{Al}_{2} \mathrm{Cu}\right)$ equilibrium composition. Given its importance for strengthening $\mathrm{Al}$, a large number of studies of the $\mathrm{Al}-\mathrm{Cu}$ precipitation sequence have focused on the properties of metastable $\theta^{\prime}[20,21]$. Relatively, little is known concerning 


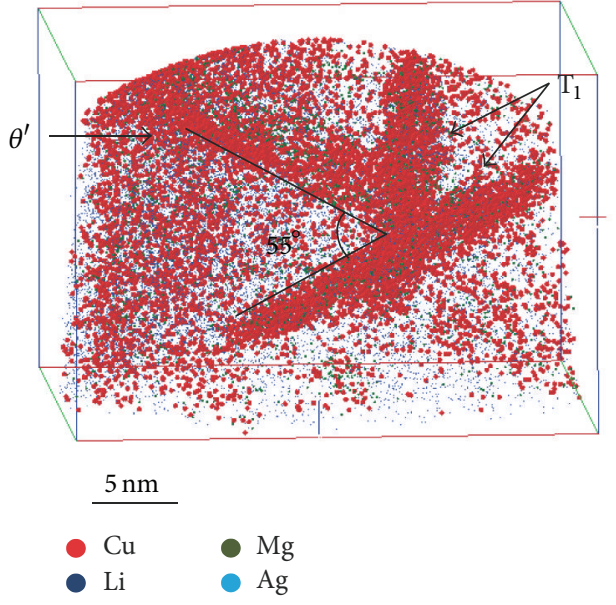

(a)

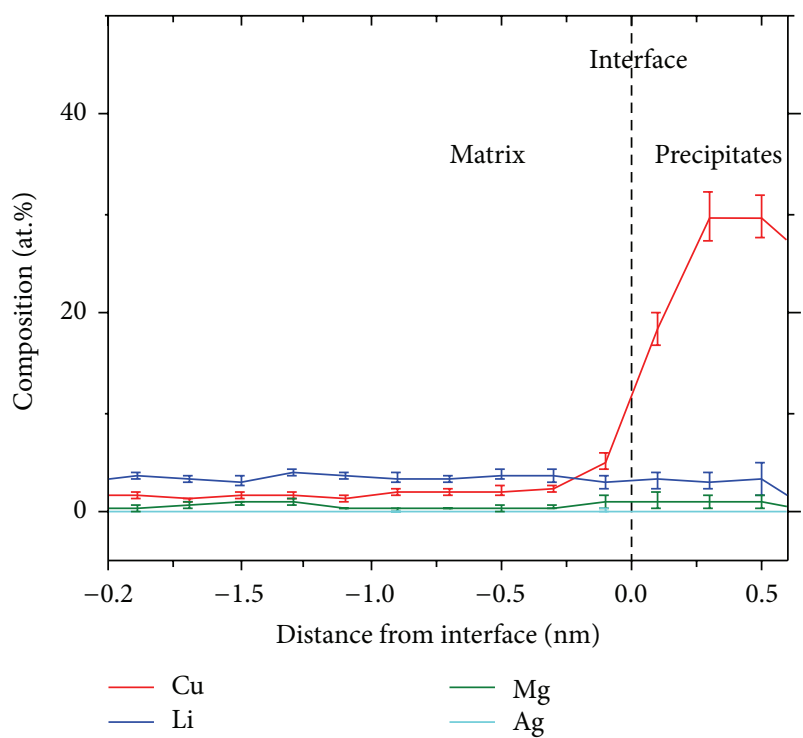

(b)

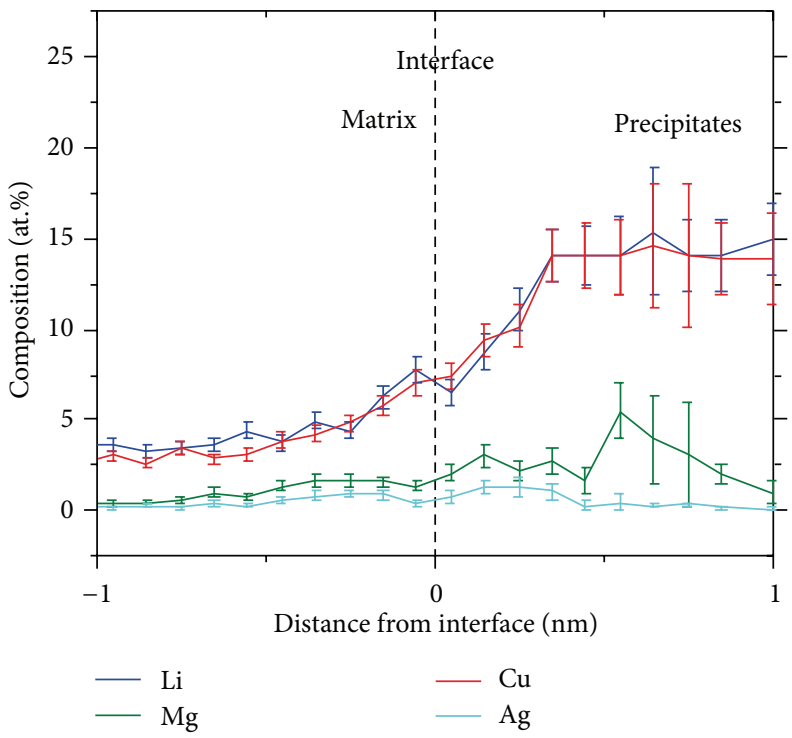

(c)

FIGURE 5: LAWATAP analysis with new experimental parameters $25 \mathrm{~K}$ and $22.5 \%$ of pulse fraction. (a) Reconstructed volume, obtained with laser assisted wide angle tomographic atom probe, shows $\mathrm{T}_{1}$ and $\theta^{\prime}$ platelets. (b) Corresponding proxigram composition profile for $\theta^{\prime}$ gives an optimistic chemical composition as $(30 \pm 2)$ at.\% $\mathrm{Cu},(3 \pm 1)$ at.\% $\mathrm{Li}$, and $(1 \pm 0.7)$ at.\% $\mathrm{Mg}$. (c) Corresponding combined proxigram composition profile for $\mathrm{T}_{1}$ with the chemical composition of $(14 \pm 1)$ at. $\% \mathrm{Cu},(14 \pm 2)$ at. $\% \mathrm{Li},(3.8 \pm 1)$ at. $\% \mathrm{Mg}$, and $(0.8 \pm 0.4)$ at. $\% \mathrm{Ag}$.

the compositional evolution of $\theta^{\prime}$ precipitates, since its nanometer-scale platelet-like morphology makes quantitative analytical electron microscopy analyses extremely difficult. Recent study by Biswas et al. [22] shows that $\theta^{\prime}$ precipitates are observed upon ageing between $190^{\circ} \mathrm{C}$ and $260^{\circ} \mathrm{C}$ in a binary $\mathrm{Al}-1.7$ at.\% $\mathrm{Cu}$ alloy. They observed that, after ageing the alloy for $8 \mathrm{~h}$ at $190^{\circ} \mathrm{C}, \theta^{\prime}$ precipitates exhibit a range of $\mathrm{Cu}$-deficient core concentration which differ from the equilibrium composition of $\left(\mathrm{Al}_{2} \mathrm{Cu}\right)$. In contrast, alloy aged at $260^{\circ} \mathrm{C}$ for $4 \mathrm{~h}$ exhibited precipitates with $\mathrm{Cu}$ core concentrations close to the equilibrium value. According to the authors, the cause of $\mathrm{Cu}$ deficiency in the $\theta^{\prime}$ precipitates at the lower ageing temperature remains an open issue. In our study, the applied T8 heat treatment implies artificial ageing of the alloy for $30 \mathrm{~h}$ at $150^{\circ} \mathrm{C}$. It is worth noting that our ageing temperature is located below the metastable solvus boundary for the $\theta^{\prime}$ precipitates in $\mathrm{Al}-\mathrm{Cu}$ phase diagram [23]. Our compositional analysis of the $\theta^{\prime}$ platelet showed the stoichiometric composition consistent with the expected $\left(\mathrm{Al}_{2} \mathrm{Cu}\right)$ equilibrium composition. This can be explained in terms of increasing the ageing time that will induce the $\mathrm{Cu}$ diffusion to the existing defects in the microstructure resulting in a core concentration close to the equilibrium one. 


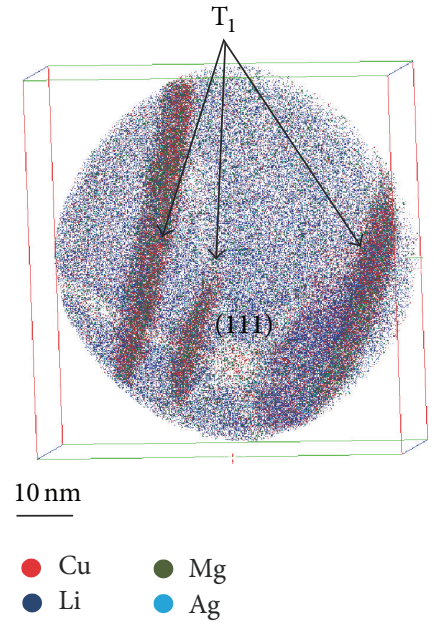

(a)

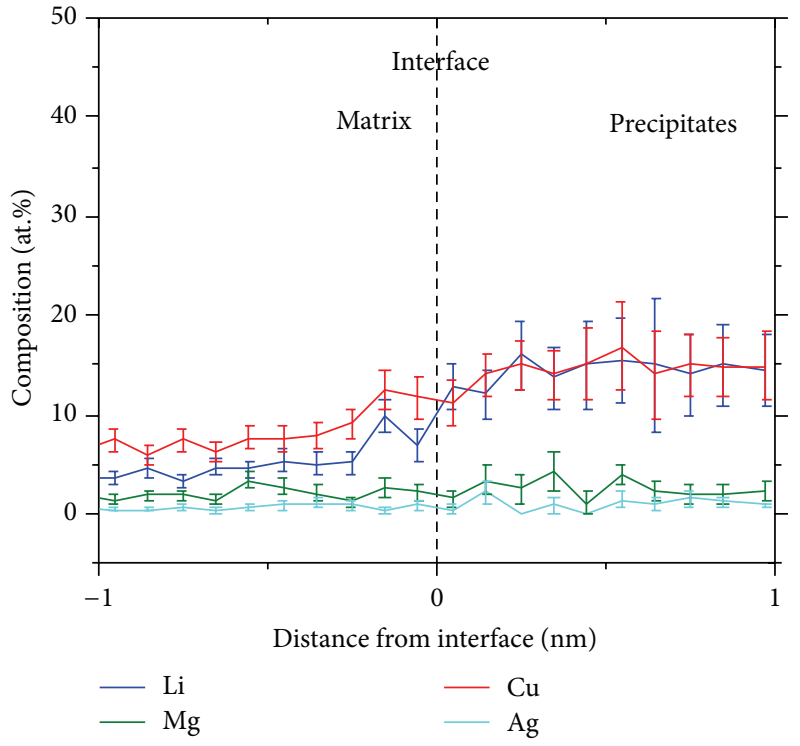

(b)

Figure 6: LEAP analysis at $22 \mathrm{~K}$ and $18 \%$ of pulse fraction. (a) Top view of the reconstructed volume of a sample shows the intersections of the $\mathrm{T}_{1}$ platelets with the (111) pole. (b) Corresponding combined proxigram composition profile for $\mathrm{T}_{1}$ with the chemical composition of $(14.3 \pm 2)$ at. $\% \mathrm{Cu},(15.5 \pm 3)$ at. $\% \mathrm{Li},(2.5 \pm 1)$ at. $\% \mathrm{Mg}$, and $(0.8 \pm 0.5)$ at. $\% \mathrm{Ag}$.

A combined proxigram profile for several $\mathrm{T}_{1}$ platelets is shown in Figure 5(c). The chemical compositions for the $\mathrm{T}_{1}$ platelets was found to be $(14 \pm 1)$ at. $\% \mathrm{Cu},(14 \pm 2)$ at. $\% \mathrm{Li},(3.8 \pm 1)$ at. $\% \mathrm{Mg}$, and $(0.8 \pm 0.4)$ at. $\% \mathrm{Ag}$. This confirms both the deviation from $\left(\mathrm{Al}_{2} \mathrm{CuLi}\right)$ stoichiometry and potential enrichment of the $\mathrm{T}_{1}$ phase with $\mathrm{Mg}$. By considering the current model proposed by Cassada et al. [7], the precipitation of the $\mathrm{T}_{1}$ phase on the $\{111\} \mathrm{Al}$ planes requires the presence of one or more partial dislocation bounded by a stacking fault. Because the stacking fault energy (SFE) of $\mathrm{Al}$ is very high, the dissociation of dislocations into partials is believed to be necessary for nucleating the $\mathrm{T}_{1}$ phase. This can be facilitated by elements known to decrease the SFE of $\mathrm{Al}$ and among these elements $\mathrm{Mg}$ and Ag have been found to be highly effective [24]. Regarding the effect of $\mathrm{Mg}$ enrichment inside the $\mathrm{T}_{1}$ platelet on the mechanical properties of the alloy, it has been shown that single addition of $\mathrm{Ag}$ in $\mathrm{Al}-\mathrm{Cu}-\mathrm{Li}-\mathrm{Zr}$ alloy had no effect on the age hardenable curve, while $\mathrm{Mg}$ addition significantly raises the peak hardness and shortens the time to the peak [6]. The peak hardness further increases when $\mathrm{Ag}$ is added together with $\mathrm{Mg}$. This effect is explained as follows. In a case of single addition of $\mathrm{Ag}$, the $\mathrm{T}_{1}$ platelet nucleated only on dislocation loop around a $\mathrm{Zr}$ dispersoids. In contrast, $\mathrm{Mg}$ addition has been revealed to cause the formation of octahedral microvoids and new GP zones on $\{111\} \mathrm{Al}$ planes; and these act as nucleation sites for the $\mathrm{T}_{1}$ phase providing a fine dispersion and hence increase the hardness of the system. Thus, it can be concluded that $\mathrm{Mg}$ and $\mathrm{Ag}$ are known to aid the precipitation of $T_{1}$ phase and hence improve the hardness of the alloy. The distribution of these elements in the structure of the $T_{1}$ platelets as well as their portioning between precipitates and matrix is the subject of conflict report [25].

3.2.3. LEAP Analyses at $22 \mathrm{~K}$ and $18 \%$ of Pulse Fraction. The use of the wider field of view of the detector in the LEAP permits the collection of larger datasets. Furthermore, using a different machine allows determining any device specific artifacts.

A top view of the reconstructed volume of a sample analyzed by a LEAP in voltage mode at $22 \mathrm{~K}$ and $18 \%$ pulse fraction is shown in Figure 6(a). The intersections of three $\mathrm{T}_{1}$ platelets with the (111) pole are visible. According to the proxigram (Figure 6(b)) from 8 at.\% Li isoconcentration surface of these platelets, this analysis yielded the close values for the chemical compositions of the $\mathrm{T}_{1}$ platelets, with (14.3 \pm $2)$ at. $\% \mathrm{Cu},(15.5 \pm 3)$ at. $\% \mathrm{Li},(2.5 \pm 1)$ at. $\% \mathrm{Mg}$, and $(0.8 \pm 0.5)$ at. $\% \mathrm{Ag}$, as LAWATAP analyses.

One should note that the observation of the $\beta^{\prime}\left(\mathrm{Al}_{3} \mathrm{Zr}\right)$ precipitates has not been recorded in APT analysis. This is simply due to the fact of the large diameter and small number density of this phase in the microstructure, which make the $\mathrm{APT}$ analyses challenging.

The combination of results from different atom probes at different experimental conditions, even including laser based results from Gault et al. [14], suggests that the actual chemical composition for the thin $\mathrm{T}_{1}$ platelets could differ from the $\left(\mathrm{Al}_{2} \mathrm{CuLi}\right)$ of the stable bulk phase, since changing the parameters should induce a change in the significance of the artifacts. Furthermore, it seems unlikely that the artifacts would only influence the $\mathrm{Cu}$ detection for the $\mathrm{T}_{1}$ platelets but not the $\theta^{\prime}$ platelets. Even if one assumes that Li changes the evaporation behavior of $\mathrm{Cu}$, it is difficult to understand 

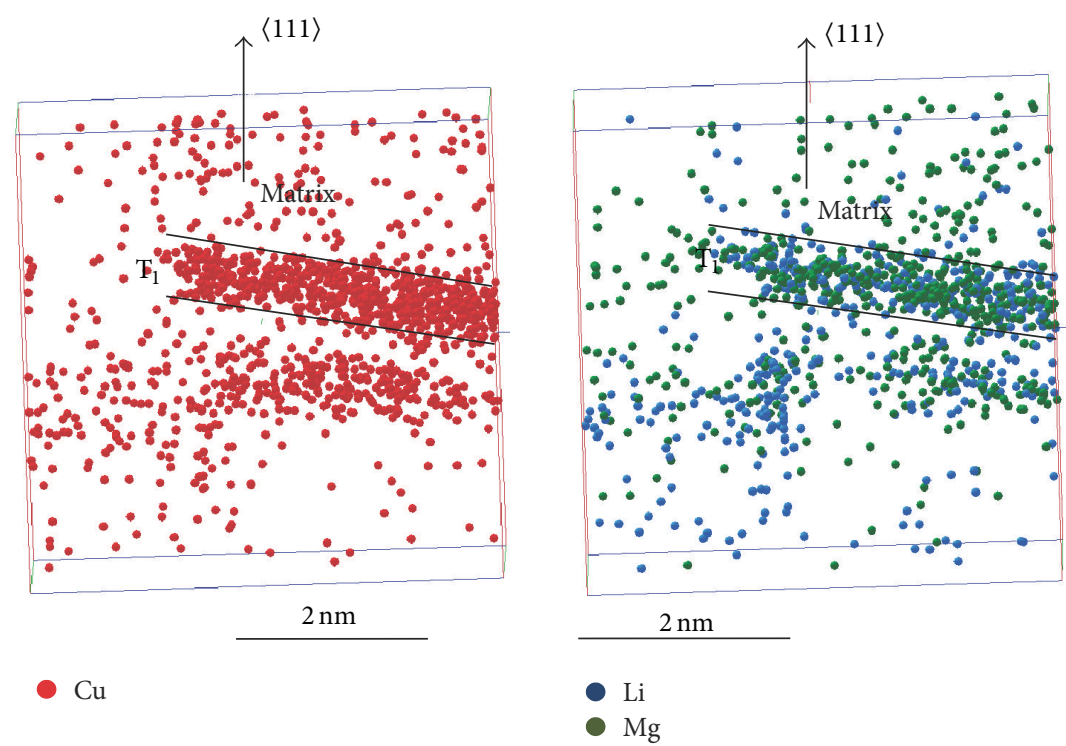

FIgURE 7: The magnified view of the $\mathrm{T}_{1}$ platelet showing the density of $\mathrm{Cu}, \mathrm{Li}$, and $\mathrm{Mg}$ atoms at the matrix/precipitates interface.

why it should not also affect $\mathrm{Al}$ and thus negate this effect. Such an effect should also result in an extremely decreased atomic density, since about half of all otherwise detected atoms would be missing. But this is not observed at the platelet positions according to the density profiles of the cylinders perpendicular to these thin platelets. In fact, the average difference between the detected atoms in the matrix and the precipitates dose not exceed 32 atoms.

In conclusion, it seems reasonable to propose that the concentration in the $T_{1}$ phase is indeed nonstoichiometric after treatment of the samples in the T8 condition. This finding is also supported by high angle annular dark field scanning transmission electron microscopy (HAADF) STEM and small angle X-ray scattering (SAXS) results from Donnadieu et al. [26]. In this study the authors investigated a similar alloy, conducting a similar thermomechanical treatment. The observed microstructure also consists of a homogenous distribution of thin platelets precipitates with $1 \mathrm{~nm}$ thickness and parallel to (111) Al planes. They noted that the composition of the layers of the thin $\mathrm{T}_{1}$ precipitates may deviate from the $\left(\mathrm{Al}_{2} \mathrm{CuLi}\right)$ stoichiometry of the stable bulk phase and proposed that this may be either due to the presence of higher $\mathrm{Al}$ content than would be expected for the $\mathrm{T}_{1}\left(\mathrm{Al}_{2} \mathrm{CuLi}\right)$ or due to the nature of the interface planes. Their results reported $\mathrm{Al}$ content higher than expected for $\mathrm{T}_{1}\left(\mathrm{Al}_{2} \mathrm{CuLi}\right)$ phase and the occurrence of matrix/ $\mathrm{T}_{1}$ interface on $\mathrm{Al}-\mathrm{Cu}$ mixed layer instead of Al-Li layer. The authors also suggested that the actual atomic structure of the thin $\mathrm{T}_{1}$ platelet could present stoichiometry different from that for the bulk $\mathrm{T}_{1}$ phase. With regard to the atomic structure of the bulk $\mathrm{T}_{1}$ phase, several models have been proposed. The first model is proposed by Huang and Ardell [27]. According to this model, the $\mathrm{T}_{1}$ phase structure consists of a stack of hexagonal layers similar to $\{111\} \mathrm{Al}$ planes. The basal plane and the medium one $(z=0$ and $1 / 2)$ are formed by a mix of Al-Li layer, while the inner planes $(z=1 / 4$ and 3/4) are hexagonal layers of $\mathrm{Cu}$ and $\mathrm{Al}$ atoms. The second proposed model of the structure of the $T_{1}$ phase has been made by Howe et al. [28]. In this model, the authors suggested that the basal plane $(z=0)$ is formed by Al layer, while the medium one $(z=1 / 2)$ is made of $\mathrm{Li}$ atoms. The inner planes $(z=1 / 4$ and $3 / 4)$ are somewhat similar to that in Huang and Ardell model. The third structure of the $T_{1}$ phase has been proposed by Van Smaalen et al. [29]. Their proposed structure displays mix of Al-Li layers for $z=0$ and $z=1 / 2$, which are corrugated, while the inner layers are corrugated Al-Cu layers. The Huang and Ardell study [27] was, until very recently, the generally accepted structure for the $T_{1}$ phase. However, the two recent and independent studies, by Donnadieu et al. [26] and Dwyer et al. [30], determined that the structure of the thin $\mathrm{T}_{1}$ platelets embedded in $\mathrm{Al}$ matrix was actually very close to that of the bulk $\mathrm{T}_{1}$ phase proposed by Van Smaalen et al. [29]. But the case might be different for the $T_{1}$ precipitates with the thickness less than one unit cell. Thus, it can be concluded that although Van Smaalen et al. [29] structure provides the basis for the structure of the $T_{1}$ precipitates, for the earliest stage of precipitation, modifications may occur.

On the other hand, more recent APT study proposed by Araullo-Peters et al. [25] reported the presence of the $T_{1}$ precursor at the early stage of ageing. However, the observed $\mathrm{T}_{1}$ platelets in this study are between 5 and $10 \mathrm{~nm}$ in thickness with the chemical compositions different from that for the bulk $\mathrm{T}_{1}$ phase.

In particular, our results demonstrated the presence of lower $\mathrm{Li}$ and $\mathrm{Cu}$ contents with 1:1 ratio in the thin $\mathrm{T}_{1}$ platelets. These results confirm the fact of the $\mathrm{Al}$ content higher than what would be expected for this phase. As far as the matrix $/ \mathrm{T}_{1}$ interface is considered, APT is more appropriate tool to investigate the local chemistry at the interface. Figure 7 displays a higher magnification image for the $\mathrm{T}_{1}$ platelet. It can be seen that the density of $\mathrm{Cu}$ 
atoms at the matrix/ $\mathrm{T}_{1}$ interface is higher than that for $\mathrm{Li}$ atoms. Moreover, the correlation between $\mathrm{Mg}$ and $\mathrm{Li}$ atoms is clearly visible. This observation confirms the assumption of the occurrence of the matrix/ $\mathrm{T}_{1}$ interface on $\mathrm{Al}-\mathrm{Cu}$ layer instead of $\mathrm{Al}-\mathrm{Li}$ layer and the consumption of the first compact Al-Li layer in the nucleation of the $\mathrm{T}_{1}$ phase. It comes out then that the composition of the $T_{1}$ precipitates deviates from that of the stable bulk phase. The deviation of the $\mathrm{T}_{1}$ phase from thermodynamic equilibrium composition for the stable bulk phase suggests that the T8 condition is corresponding to the thermodynamical nonequilibrium condition. The obtained microstructure in this condition has appreciable supersaturation of defects, which means that the nucleation and growth of different phases are still at their intermediate stages.

\section{Conclusion}

This paper reports a characterization of the commercial aluminum-lithium-copper alloy AA2195 in the T8 condition using electron microscopy and atom probe tomography. The results confirm that the microstructure of the alloy in this temper state consists of platelet-shaped $\mathrm{T}_{1}\left(\mathrm{Al}_{2} \mathrm{CuLi}\right), \theta^{\prime}\left(\mathrm{Al}_{2} \mathrm{Cu}\right)$, and spherical $\beta^{\prime}\left(\mathrm{Al}_{3} \mathrm{Zr}\right)$ precipitates.

Owing to the ability of atom probe tomography to resolve the chemical position on a subnanometer scale, compositional analyses of thin platelet precipitates (less than $2 \mathrm{~nm}$ ) have been performed. The measured $\theta^{\prime}$ stoichiometry is consistent with the expected $\left(\mathrm{Al}_{2} \mathrm{Cu}\right)$ equilibrium composition with a significant partitioning of $\mathrm{Li}$ atoms within this precipitate. For the $\mathrm{T}_{1}$ platelets, a deviation from the stoichiometric $\left(\mathrm{Al}_{2} \mathrm{CuLi}\right)$ of the bulk phase was observed. This phase is enriched with $\mathrm{Mg}$ atoms without any indication of the presence of $\mathrm{Mg}$ and $\mathrm{Ag}$ atoms at the phase/matrix interface. The off-stoichiometry of the thin $\mathrm{T}_{1}$ platelet cannot be simply attributed to artifacts in the APT measurements and might be considered as a true deviation from the thermodynamic equilibrium composition of the thin $\mathrm{T}_{1}$ platelets for the stable bulk phase.

\section{Disclosure}

Professor Dr. Talaat Al-Kassab is currently on leave from Physical Sciences and Engineering Division, King Abdullah University of Science and Technology (KAUST).

\section{Conflict of Interests}

The authors declare that there is no conflict of interests regarding the publication of this paper.

\section{Acknowledgments}

The authors thank Dr. Dalaver H. Anjum (Imaging and Characterization Core Lab-KAUST) for his support with electron tomography. Ferdinand Haider acknowledges financial support provided to him during his visits at King
Abdullah University of Science and Technology (KAUST). Talaat Al-Kassab gratefully acknowledges financial support provided to him through King Abdullah University of Science and Technology (KAUST) baseline funding program.

\section{References}

[1] J. R. Pickens, F. H. Heubaum, T. J. Langan, and L. S. Kramer, "Aluminum-lithium alloys," in Proceedings of the 5th International Aluminum-Lithium Conference, T. H. Sanders and E. A. Starke, Eds., p. 1397, MCE Publications, Birmingham, UK, March 1989.

[2] E. A. Starke Jr. and B. N. Bhatm, "Technical summary," in Proceedings of the Aluminum-Lithium Alloys for Aerospace Applications Workshop, B. N. Bhat, T. T. Bales, and E. J. Vesely Jr., Eds., NASA Conference Publication 3287, pp. 3-5, Marshall Space Flight Center, Huntsville, Ala, USA, 1994.

[3] R. Crooks, Z. Wang, V. I. Levit, and R. N. Shenoy, "Microtexture, micro structure and plastic anisotropy of AA2195," Materials Science and Engineering A, vol. 257, no. 1, pp. 145-152, 1998.

[4] Z. M. Wang and R. N. Shenoy, "Microstructural characterization of aluminum-lithium alloys 1460 and 2195," Report 206914, NASA Langley Research Center, Hampton, Va, USA, 1998.

[5] P. S. Chen and B. N. Bhat, "Time-temperature-precipitation behavior in Al-Li alloy 2195," Report No. 211548, NASA/TM, Huntsville, Ala, USA, 2002.

[6] G. Itoh, Q. Cui, and M. Kanno, "Effects of a small addition of magnesium and silver on the precipitation of $\mathrm{T} 1$ phase in an $\mathrm{Al}$ 4\%Cu-1.1\%Li-0.2\%Zr alloy," Materials Science and Engineering: A, vol. 211, no. 1-2, pp. 128-137, 1996.

[7] W. A. Cassada, G. J. Shiflet, and E. A. Starke, “The effect of plastic deformation on $\mathrm{Al}_{2} \mathrm{CuLi}\left(\mathrm{T}_{1}\right)$ precipitation," Metallurgical Transactions A, vol. 22, no. 2, pp. 299-306, 1991.

[8] C. Laird and H. I. Aaronson, "Structures and migration kinetics of alpha:theta prime boundaries in aluminum-4\% copper. I. Interfacial structures," Transactions of the Metallurgical Society of AIME, vol. 242, p. 1393, 1968.

[9] E. A. Starke Jr. and J. T. Staley, "Application of modern aluminum alloys to aircraft," Progress in Aerospace Sciences, vol. 32, no. 2-3, pp. 131-172, 1996.

[10] A. Menand, T. Al-Kassab, S. Chambreland, and J. M. Sarrau, "Atom-probe study of aluminium-lithium alloys," Le Journal de Physique Colloques, vol. 49, no. 6, pp. C6-353-C6-358, 1988.

[11] L. A. H. Terrones and S. N. Monteir, "Composite precipitates in a commercial Al-Li-Cu-Mg-Zr alloy," Materials Characterization, vol. 58, no. 2, pp. 156-161, 2007.

[12] G. Schmitz, K. Hono, and P. Haasen, "High resolution electron microscopy of the early decomposition stage of Al $\square$ Li alloys," Acta Metallurgica et Materialia, vol. 42, no. 1, pp. 201-211, 1994.

[13] M. Murayama and K. Hono, "Role of Ag and Mg on precipitation of $\mathrm{T}_{1}$ phase in an Al-Cu-Li-Mg-Ag alloy," Scripta Materialia, vol. 44, no. 4, pp. 701-706, 2001.

[14] B. Gault, F. de Geuser, L. Bourgeois, B. M. Gabble, S. P. Ringer, and B. C. Muddle, "Atom probe tomography and transmission electron microscopy characterisation of precipitation in an Al$\mathrm{Cu}-\mathrm{Li}-\mathrm{Mg}$-Ag alloy," Ultramicroscopy, vol. 111, no. 6, pp. 683689, 2011.

[15] O. C. Hellman, J. A. Vandenbroucke, J. Rüsing, D. Isheim, and D. N. Seidman, "Analysis of three-dimensional atom-probe data by the proximity histogram," Microscopy and Microanalysis, vol. 6, no. 5, pp. 437-444, 2000. 
[16] O. C. Hellman, J. B. Du Rivage, and D. N. Seidman, "Efficient sampling for three-dimensional atom probe microscopy data," Ultramicroscopy, vol. 95, pp. 199-205, 2003.

[17] K. H. Lee, Y. J. Lee, and K. Hiraga, "Precipitation behavior in the early stage of aging in an Al-Li॰Cu-Mg-Zr-Ag (Weldalite 049) alloy, Journal of Materials Research, vol. 14, no. 2, pp. 384-389, 1999.

[18] S. H. Kellington, D. Loveridge, and J. M. Titman, "The lattice parameters of some alloys of Li," Journal of Physics D: Applied Physics, vol. 2, no. 8, article 1162, 1969.

[19] F. Vurpillot, A. Bostel, A. Menand, and D. Blavette, “Trajectories of field emitted ions in 3D atom-probe," The European Physical Journal-Applied Physics, vol. 6, no. 2, pp. 217-221, 1999.

[20] V. Vaithyanathan, C. Wolverton, and L. Q. Chen, "Multiscale modeling of precipitate microstructure evolution," Physical Review Letters, vol. 88, Article ID 125503, 2002.

[21] V. Vaithyanathan, C. Wolverton, and L. Q. Chen, "Multiscale modeling of $\theta^{\prime}$ precipitation in Al-Cu binary alloys," Acta Materialia, vol. 52, no. 10, pp. 2973-2987, 2004.

[22] A. Biswas, D. J. Siegel, C. Wolverton, and D. N. Seidman, "Precipitates in Al-Cu alloys revisited: atom-probe tomographic experiments and first-principles calculations of compositional evolution and interfacial segregation," Acta Materialia, vol. 59, no. 15, pp. 6187-6204, 2011.

[23] S. P. Ringer and K. Hono, "Microstructural evolution and age hardening in aluminium alloys: atom probe field-ion microscopy and transmission electron microscopy studies," Materials Characterization, vol. 44, no. 1-2, pp. 101-131, 2000.

[24] T. C. Schulthess, P. E. A. Turchi, A. Gonis, and T. Nieh, "Systematic study of stacking fault energies of random Al-based alloys," Acta Materialia, vol. 46, no. 6, pp. 2215-2221, 1998.

[25] V. Araullo-Peters, B. Gault, F. D. Geuser, A. Deschamps, and J. M. Cairney, "Microstructural evolution during ageing of $\mathrm{Al}-\mathrm{Cu}-$ Li-x alloys," Acta Materialia, vol. 66, pp. 199-208, 2014.

[26] P. Donnadieu, Y. Shao, F. de Geuser et al., "Atomic structure of $\mathrm{T}_{1}$ precipitates in $\mathrm{Al}-\mathrm{Li}-\mathrm{Cu}$ alloys revisited with HAADFSTEM imaging and small-angle X-ray scattering," Acta Materialia, vol. 59, no. 2, pp. 462-472, 2011.

[27] J. C. Huang and A. J. Ardell, "On the crystal structure and stability of the T1 precipitates in aged Al-Li-Cu alloys," Materials Science and Technology, vol. 3, pp. 176-188, 1987.

[28] J. M. Howe, J. Lee, and A. K. Vasudevan, "Structure and deformation behavior of $\mathrm{T}_{1}$ precipitate plates in an Al-2Li-1 Cu alloy," Metallurgical Transactions A, vol. 19, no. 12, pp. 2911-2920, 1988.

[29] S. Van Smaalen, A. Meetsa, J. L. de Boer, and P. M. Bronsveld, "Refinement of the crystal structure of hexagonal $\mathrm{Al}_{2} \mathrm{CuLi}$," Journal of Solid State Chemistry, vol. 85, no. 2, pp. 293-298, 1990.

[30] C. Dwyer, M. Weyland, L. Y. Chang, and B. C. Muddle, "Combined electron beam imaging and ab initio modeling of $\mathrm{T}_{1}$ precipitates in Al-Li-Cu alloys," Applied Physics Letters, vol. 98, no. 20, Article ID 201909, 2011. 

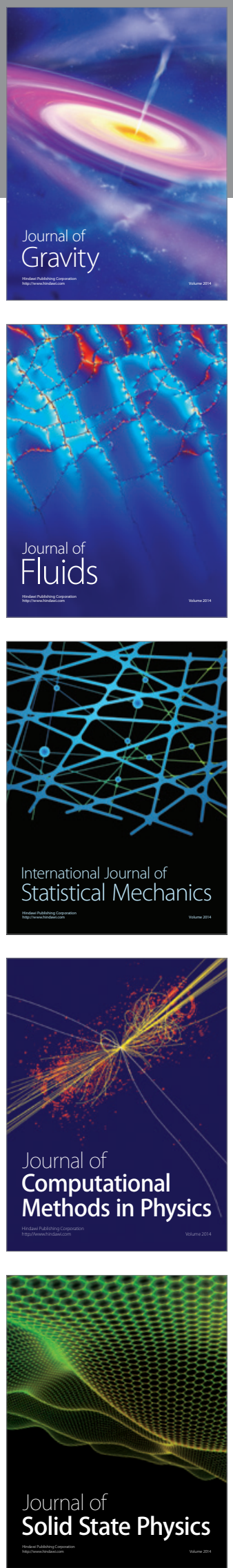

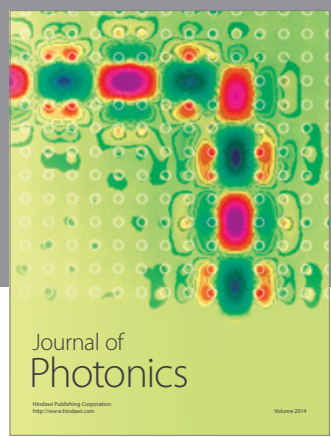

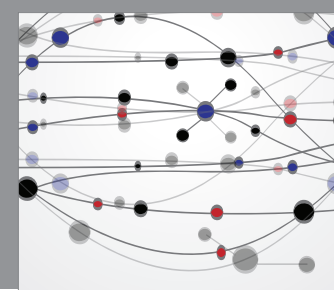

The Scientific World Journal

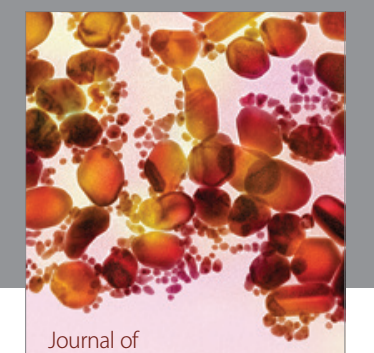

Soft Matter
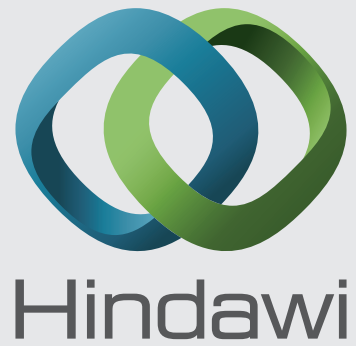

Submit your manuscripts at

http://www.hindawi.com
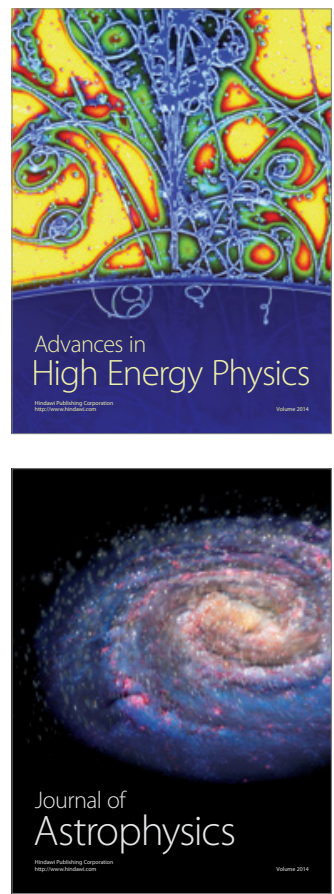
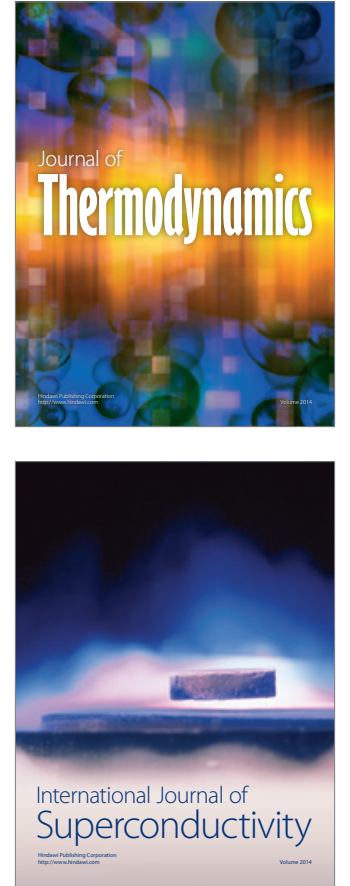
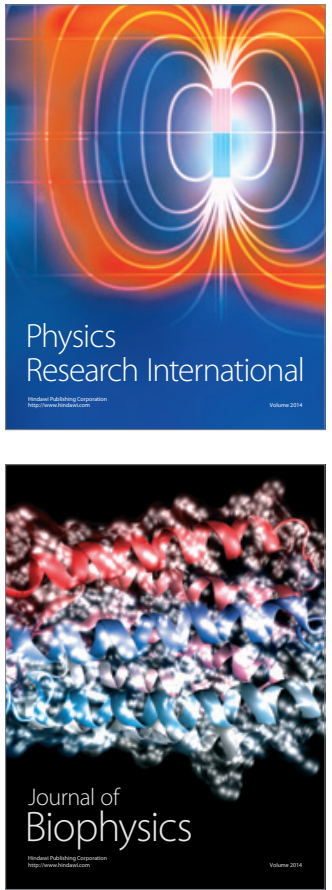
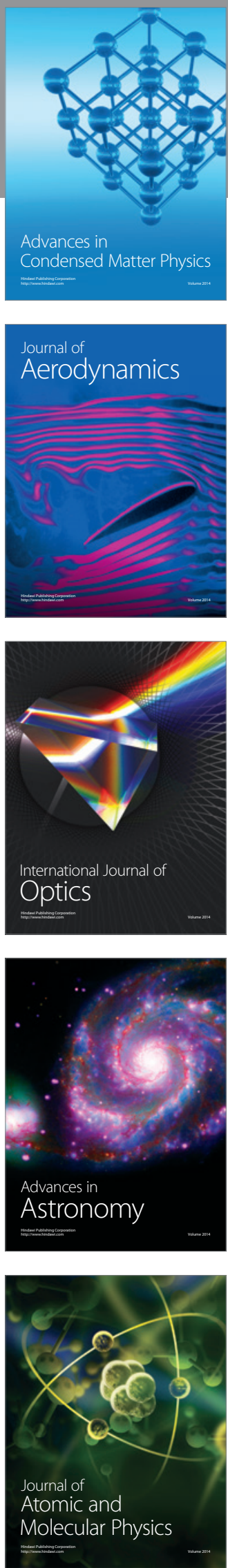